\title{
The Success of Healthcare Providers Who Fought the Epidemic of the Meiji Era in Mizunami City, Gifu Prefecture, Japan
}

\author{
Yuko Harding ${ }^{*}\left(\mathbb{D}\right.$, Shinji Sunada², Masako Yano ${ }^{3}$ \\ ${ }^{1}$ Faculty of Nursing, Chukyo Gakuin University, Mizunami, Japan \\ ${ }^{2}$ Mizunami City Board of Education, Mizunami, Japan \\ ${ }^{3}$ Faculty of Nursing, St. Mary's College, Kurume, Japan \\ Email: *yukohardinaha@yahoo.co.jp
}

How to cite this paper: Harding, Y., Sunada, S. and Yano, M. (2021) The Success of Healthcare Providers Who Fought the Epidemic of the Meiji Era in Mizunami City, Gifu Prefecture, Japan. Open Journal of Nursing, 11, 204-217.

https://doi.org/10.4236/ojn.2021.113018

Received: January 15, 2021

Accepted: March 27, 2021

Published: March 30, 2021

Copyright $\odot 2021$ by author(s) and Scientific Research Publishing Inc. This work is licensed under the Creative Commons Attribution-NonCommercial International License (CC BY-NC 4.0). http://creativecommons.org/licenses/by-nc/4.0/

\begin{abstract}
Introduction: Knowing an epidemic existed in Mizunami city and knowing the healthcare provided to overcome the disease may give hints on how the epidemic was handled. Aim: To examine the literature on the epidemic that occurred in the Meiji era and the contributions of healthcare providers who were active in the history of Mizunami city. Method: This is a historical study, mainly using literature. In collaboration with the Mizunami City Board of Education, we searched for materials stored by Mizunami city. In addition, with the cooperation of the local residents of the healthcare providers who were active in Mizunami city, we collected materials in reference to our purpose. Result: The outbreak of the epidemic near Mizunami city was seen as a fight against smallpox. In addition, cholera, dysentery, Spanish flu, and typhoid fever also occurred. Vaccinations were carried out in the Tono region. Healthcare providers who were active in the Meiji era include six doctors and two midwives. Discussion: In the future, it will be necessary to provide more in-depth evidence through surveys, such as interviews with the cooperation of relatives of the active healthcare providers. Conclusion: In the Meiji era, in the vicinity of Mizunami city, doctors and midwives actively fought against epidemics, such as smallpox and other infectious diseases.
\end{abstract}

\section{Keywords}

Healthcare Provider, Meiji Era, Mizunami City, Vaccination, Epidemic

\section{Introduction}

Japan changed its policy to open in 1854 . Along with this, people were hit by the 
invasion of highly lethal acute infectious diseases [1]. Smallpox became prevalent in 1874 (Meiji 7th) and 1876 (Meiji 9th), and vaccinations became widespread [2].

The infectious diseases that were prevalent in the Meiji era were mainly cholera, dysentery, typhoid fever, and pulmonary tuberculosis [3] [4]. In 1879, the number of cholera patients reached 120,000 , and it became a pandemic. Then, dysentery became a pandemic in 1893-1894 (Meiji 26th-27th), and the number of dysentery patients reached $150,000-160,000^{3}$. From the late Meiji era, pulmonary tuberculosis is prevalent. In particular, since 1910, the annual death toll from tuberculosis has reached more than 100,000 [3] [5].

The focus of public health was on measures against acute infectious diseases, and hygiene administration was in place. The frontline activities were entrusted to the police. In this way, under strong centralization, the health care system was expanded. Statistics, which are the core of the health and medical information system, started with mortality statistics in 1876 and vital statistics in 1899. Data on the number of births and deaths were collected, and the method of policy formulation based on scientific evidence was paved, boosting the capacity of health care administration [4].

Mizunami city is located in Gifu prefecture, about an hour by train from Nagoya, near Nagano prefecture, and in Tono region including Tajimi city, Toki city, Mizunami city, Ena city, and Nakatsugawa city (Figure 1). There are very few previous studies on the epidemic that occurred in the past and the contributions of healthcare providers around Mizunami city. Clarifying those situations may give us suggestions for how to cope with and overcome the modern epidemic.

Hence, we will report on the literature on the epidemic that occurred in the Meiji era and the contributions of healthcare providers who were active in the history of Mizunami city.

\section{Definitions of the Terms}

An epidemic is a widespread occurrence of an infectious disease in a community at a particular time. It means a sudden, widespread occurrence of a particular undesirable phenomenon [6].

A Healthcare provider is one who directly or indirectly administers interventions that are designed to improve the physical or emotional status of patients; or. And it also means a person licensed, certified, or otherwise authorized or permitted by law to administer healthcare [7].

\section{Aim}

The purpose of this study is to examine the literature on the epidemic that occurred in the Meiji era and the contributions of healthcare providers who were active in the history of Mizunami city and to clarify its historical significance.

\section{Method}

This is a historical study, mainly using literature. 


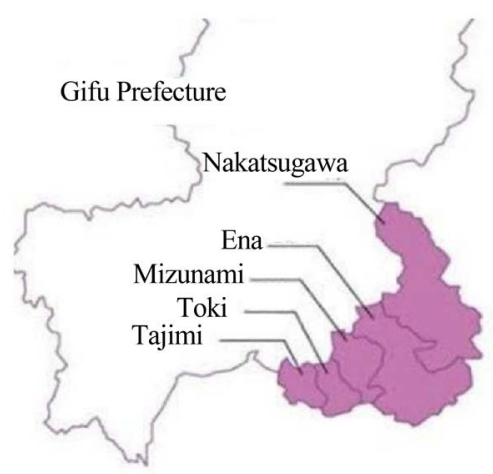

Figure 1. Location of Tono Region.

First of all, when examining the literature, through July 2020, the following databases, Ichushi-Web, the Internet-based retrieval service by Japan Medical Abstracts Society (JAMAS) [8], MEDLINE [9]/PubMed [10], Cochrane Library [11], and Google Scholar [12] were searched by the first author to find additional studies related to the topic, as were the reference lists of included papers and related reviews. Search terms included a combination of keywords by thesaurus, i.e., healthcare provider, history, Gifu prefecture, history of medicine, and Mizunami. The retrieval year was the whole year and the articles published were peer-reviewed.

Articles were excluded if the research subjects who were not healthcare providers, not focusing on the epidemic or the history of medicine, or the contributions of healthcare providers who were active in Gifu prefecture, Tono region or around Mizunami city, and re-listing of duplicate documents. No further restrictions were made. The titles of all retrieved articles were reviewed by the author; titles not meeting the predefined inclusion criteria were excluded.

Next, in collaboration with some members of the Mizunami city Board of Education, we searched for materials stored by Mizunami city.

Then, the facts were verified in the description of the purpose in the history section of each city history and the description items in the material section of Mizunami and around city history.

In addition, with the cooperation of the local residents of the healthcare providers who were active in Mizunami city, we collected materials in reference to our purpose.

As an ethical consideration, the materials used in this study were approved by the publisher. Moreover, the photographs here have been approved by the owner/ institution.

Here, we report on the history of the epidemic of the Meiji era in Mizunami city and the healthcare providers who were active in that era by conducting philological research.

\section{Result}

1) Trends in research on the epidemic that occurred in Mizunami city and the healthcare providers who fought against it. 
In the search process, 16 documents that were from the combination of health care provider, history and Gifu prefecture were found on the Ichushi-Web, but the documents that met the purpose of this study did not correspond. None of them was related to Mizunami.

None of the foreign documents met the purpose. Currently, the only materials related to the history of healthcare held by the Mizunami City Board of Education and the Mizunami city Library was as follows.

They are "Mizunami City History [13]," "Ena City History [14]," "Toki City History [15]," "Tajimi City History [16]," "Gifu Prefecture History [17] [18]" and "Mizunami's hometown and personal history [19]," compiled by the school principals who retired in Mizunami city and "The 80 years history of Mizunami Hospital [20]" (Table 1).

In the above material, some medical statistics on the outbreak of epidemics after the Meiji era in Mizunami city were described. However, there were few documents on Mizunami's healthcare's history before the Meiji period.

Moreover, the only material on the outbreak of the epidemic in Mizunami city and the healthcare providers who were active in that era was identified with reference to Mizunami's hometown and personal history [19].

The materials used to verify the facts were the description of the purpose in the history section and the material section of each city history [13]-[18].

2) The outbreak of epidemics in the Meiji era near Mizunami city (Table 2).

The outbreak of epidemics in the vicinity of Mizunami city was seen during the Kaei era as a battle against smallpox. During the Kaei era (1848-53), Yamada Gendo, a doctor in Nakanoho village (Ena city), carried out vaccinations in the Naegi Domain (Nakatsugawa city) [14]. In 1872 (Meiji 5th), Gifu prefecture has spread and thoroughly promoted vaccinations against smallpox to each kocho (head of towns and village) [15] [17]. In 1874 (Meiji 7th), vaccination institutions were set up in various places in the Tono region [14] [15]. In 1881 (Meiji 14th), Gifu prefecture assigned county doctors to each county. The county doctor was officially recognized by the Hygiene Society for a term of five years and was appointed by a prefectural ordinance [14] [17] [18]. In 1886 (Meiji 19th), a cholera epidemic occurred in Nagano prefecture, and a quarantine branch was set up in the Nakatsugawa police station and a quarantine branch office was set up in Nakatsugawa city [15].

In 1893 (Meiji 26th), the Hygiene administration affairs were transferred from the Ministry of Interior to the Police Department [14] [17] [18]. In 1896 (Meiji 29th), dysentery was prevalent in Ena city and Mizunami city, and typhoid fever was prevalent in Tajimi city. In 1905-07 (Meiji 38th-40th), dysentery was prevalent in Tajimi city. In 1918 (Taisyo 7th), an epidemic flu (Spanish flu) was prevalent in Tajimi city. In 1926 (Taisyo 15th/ Showa 1st), typhoid fever was prevalent in Tajimi city. In 1871 (Meiji 4th), the book "Nostalgic Photobook" [21] published by Mizunami city Public Library contained the state of the smallpox epidemic in 1935 (Showa 10th) [16] (Figure 2). 


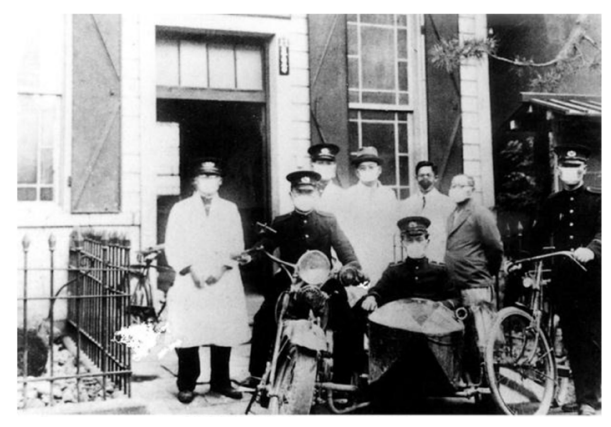

Figure 2. Police station during the smallpox epidemic of 1935 (Showa 10th) [20].

Table 1. Literature on the outbreak of epidemics and healthcare providers who were active, in the Meiji era near Mizunami city.

\begin{tabular}{cc}
\hline Publisher, Publication year & Title \\
\hline Mizunami city, 1972 & Mizunami City History, History/Historical materials [13] \\
Ena city, 1993 & Ena City History, Overview of the history, Vol.3 (1) [14] \\
Toki city, 1974 & Toki City History (3), Vol. 1/Vol. 2 [15] \\
Tajimi city, 1987 & Tajimi City History, Overview of the history, Vol. $2[16]$ \\
Gifu prefecture, 1967 & Gifu Prefecture History, Overview of the modern history, Vol. 1 [17] \\
Gifu prefecture, 1972 & Gifu Prefecture History, Overview of the modern history, Vol. 2 [18] \\
Mizunami City Retirement Principals Association, 1995 & Mizunami's Hometown and Personal History [19] \\
Medical Corporation Jinaikai Mizunami Hospital, 1988 & The 80 years history of Mizunami Hospital [20] \\
\hline
\end{tabular}

Table 2. The outbreak of epidemics in the Meiji era near Mizunami city.

\begin{tabular}{|c|c|c|}
\hline Japanese Calendar & Year & Event \\
\hline Kaei era & $1848-53$ & $\begin{array}{l}\text { Vaccinations against smallpox conducted by Gendo Yamada, a doctor in Ena-gun Nakanoho village } \\
\text { (Ena city), in the Naegi Domain (Nakatsugawa city) [14] }\end{array}$ \\
\hline Meiji 5th & 1872 & $\begin{array}{l}\text { Dissemination and thoroughness of vaccinations against smallpox to each kocho (head of towns and } \\
\text { village) by Gifu prefecture [15] [17] }\end{array}$ \\
\hline Meiji 7th & 1874 & $\begin{array}{l}\text { By this time, installation of the vaccination institution in one place each in Tono region: Toki-gun } \\
\text { Takayama village (Toki city), Tajimi Town (Tajimi city), Toki village (Mizunami city), Ena District Oi } \\
\text { village, Iwamura, Akechi village, Nakanoho (Ena city), Naegi village (Nakatsugawa city) [14] [15] }\end{array}$ \\
\hline Meiji 14th & 1881 & $\begin{array}{l}\text { Decide on an arrangement of county doctor by Gifu prefecture, and the distribution of two county } \\
\text { doctors to Ena-gun (Ena city and Nakatsugawa city). County doctor's tenure of office was } 5 \text { years. The } \\
\text { county doctor was elected by the Hygiene Society and appointed by the prefectural ordinance [14] [17] } \\
{[18] \text {. }}\end{array}$ \\
\hline Meiji 26th-Showa 17th & 1893 & $\begin{array}{l}\text { Hygiene administration affairs transferred from the Interior Department to the Police Department [14] } \\
\text { [17] [18] }\end{array}$ \\
\hline Meiji 29th & 1896 & $\begin{array}{l}\text { Infectious epidemic of Dysentery in Iwamura (Ena city) and Kamado (Mizunami city) and Typhoid } \\
\text { fever in Kasahara (Tajimi city) [16] }\end{array}$ \\
\hline Meiji 38th-40th & $1905-07$ & Dysentery outbreak in Koizumi and Ikeda (Tajimi city) [16] \\
\hline Taisho7th & 1918 & Epidemic flu (Spanish flu) in Tajimi city [16] \\
\hline Taisho 15th/ Showa 1st & 1926 & Typhoid fever epidemic in Tajimi city [16] \\
\hline
\end{tabular}


3) Healthcare providers who were active in the Meiji era (Table 3).

Healthcare providers who were active in the Meiji era include six doctors and two midwives called Sanba or Jyosanpu in Japanese. The midwife called Sanba is the name when the midwifery (Sanba) rule and the midwifery list registration rule was promulgated in 1899 (Meiji 32nd). In 1948 (Showa 23rd), the name was changed to midwife (called Jyosanpu), and in 2002 (Heisei 14th) it was changed to midwife (called Jyosanshi).

Dr. Jyusaku Hirako (birth and death years: 1822-1888; Bunsei 5th-Meiji 21st) carried out vaccinations against smallpox in 1850 (Kaei 3rd). In 1871 (Meiji 4th), the vaccination institution against smallpox was opened in Mizunami city. The application for permission to open the vaccination institution against smallpox at that time was published in Mizunami City History (Figure 3) [13] [15].

He practiced medicine as a Chinese medicine doctor, opened a terakoya (a private school), and was involved in education [13] [19]. There is Dr. Jyusaku's grave at Koido Reien in Inatsu-cho, Mizunami city (Figure 4).

Dr. Gendo Yamada (birth and death years: 1824-1874; Bunsei 7th-Meiji 7th) also carried out vaccinations against smallpox during the Kaei era around the same time as Dr. Jyusaku. In 1872 (Meiji 5th), he was a vaccination doctor against at the vaccination institution smallpox in Nakanoho village, Ena city.

The photo shows after the death of Gendo Yamada, the record book of vaccinations against smallpox in Nakanoho village, Ena city (Figure 5) [14], the vaccination certificate in Ena city in 1897 (Figure 6) [14], and the vaccination certificate with the seal of the pharmaceutical company (Figure 7) [14].

As vaccination documents kept by Okusa Ward in Toki-cho, Mizunami city show the personnel interrogation report of vaccinations against smallpox in 1884 (Figure 8).

Dr. Hoju Watarai (birth and death years: 1872-1932; Meiji 5th-Showa 7th) served as a military doctor during the Russo-Japanese War after graduating from the Jikei University School of Medicine. He practiced medicine in Kamado village (Mizunami city) in 1884. It is said that he rushed around Mizunami city with a horse and provided first aid and was tolerant of delinquent medical fees. He was involved in the development of Ryugin Falls in the Kamado area of Mizunami city. It is presumed that he was a gynecologist, but it is unconfirmed [13] [19].

Dr. Tsunejiro Kumagai (year of birth: 1873-1961; Meiji 6th-Showa 36th) was a surgeon (burn) doctor. He worked as an apprentice at a doctor's house in Yokohama in 1891, passed the first half of the doctor's practice examination in 1898, passed the second half of the same examination in 1899, and worked at Juntendo Hospital. He was enrolled as a medical selection student at Tokyo Imperial University in 1900. And he opened Kumagaya Hospital in Izumi village (Toki city). He became the mayor of Izumi in 1936 and became a member of the Gifu Prefectural Assembly in 1937 concurrently serving as the mayor [13] [19]. 
Table 3. Healthcare providers who were active in the Meiji era.

\begin{tabular}{|c|c|c|c|}
\hline Japanese Calendar & Year & Healthcare provider & Activities of Healthcare Providers \\
\hline \multirow{3}{*}{$\begin{array}{l}\text { Bunsei 5th-Meiji } \\
21 \text { st }\end{array}$} & \multirow{3}{*}{$1822-1888$} & \multirow{3}{*}{$\begin{array}{l}\text { Dr. Jyusaku Hirako } \\
\text { Died at } 66 .\end{array}$} & 1850 (Kaei 3rd) Implementation of vaccinations against smallpox \\
\hline & & & $\begin{array}{l}1871 \text { (Meiji 4th) Established the vaccination institution against smallpox } \\
\text { (Masumi, Toki-cho, Mizunami city) }\end{array}$ \\
\hline & & & Practice medicine (Chinese medicine), Opening of terakoya-education \\
\hline \multirow{2}{*}{$\begin{array}{l}\text { Bunsei 7th-Meiji } \\
\text { 7th }\end{array}$} & \multirow[b]{2}{*}{$1824-1874$} & \multirow{2}{*}{$\begin{array}{l}\text { Dr. Gendo Yamada } \\
\text { Died at } 50 .\end{array}$} & Kaei era (1843-1853) Implementation of vaccinations against smallpox \\
\hline & & & $\begin{array}{l}1872 \text { (Meiji 5th): as vaccination doctor at the vaccination institution against smallpox } \\
\text { (Nakanoho village, Ena city) }\end{array}$ \\
\hline \multirow{5}{*}{$\begin{array}{l}\text { Meiji 5th-Showa } \\
\text { 7th }\end{array}$} & \multirow{5}{*}{$1872-1932$} & \multirow{5}{*}{$\begin{array}{l}\text { Dr. Hoju Watarai } \\
\text { Died at } 60 .\end{array}$} & Graduated from Jikei University School of Medicine \\
\hline & & & Served as a military doctor during the Russo-Japanese War \\
\hline & & & Practice medicine in Kamado village (Mizunami city) in 1884 \\
\hline & & & 1911 (Meiji 44th) Practice medicine (Kamado Villege, Mizunami city) \\
\hline & & & Contributed to the development of Ryugin Falls (Kamado village) \\
\hline \multirow{8}{*}{$\begin{array}{l}\text { Meiji 6th- } \\
\text { Showa 36th }\end{array}$} & \multirow{8}{*}{$1873-1961$} & & Surgeon (burn) doctor \\
\hline & & & 1891 (Meiji 24th) Apprentice at a doctor's house in Yokohama \\
\hline & & & 1898 (Meiji 31st) Passed the first half of the doctor's practice exam \\
\hline & & Dr. Tsunejiro Kumagai & 1899 (Meiji 32nd) Passed the latter term examination and worked at Juntendo \\
\hline & & Died at 88 . & Hospital \\
\hline & & & $\begin{array}{l}1900 \text { (Meiji 33th) Enrolled as a medical selection student at Tokyo Imperial University, } \\
\text { opened Kumagaya Hospital in Izumi village (Toki city) }\end{array}$ \\
\hline & & & 1936 (Showa 11th) Mayor Izumi \\
\hline & & & 1937 (Shouwa 12th) Gifu Prefectural Assembly member (serves as the mayor) \\
\hline \multirow{7}{*}{$\begin{array}{l}\text { Meiji 12th- } \\
\text { Syouwa 34th }\end{array}$} & \multirow{7}{*}{$1879-1959$} & & $\begin{array}{l}1903 \text { (Meiji 36th) Entered Gifu prefecture midwifery/nurse training center, graduated the } \\
\text { following year }\end{array}$ \\
\hline & & & Worked as a nurse at Kanazawa Preparatory Hospital during the Russo-Japanese War \\
\hline & & Midwife. & 1905 (Meiji 38th) Opening of midwifery business (Mizunami village) \\
\hline & & Tei Oishi & Delivery assistance of 400 babies a year as a Midwife for about 50 years after the \\
\hline & & Died at 80. & Russo-Japanese War \\
\hline & & & $\begin{array}{l}1942 \text { (Showa 17th) Awarded a letter of appreciation by the Gifu branch manager of the } \\
\text { Patriotic Women's Association }\end{array}$ \\
\hline & & & After the war, teaching mothers' classes, activity in the housekeepers' association \\
\hline \multirow{7}{*}{$\begin{array}{l}\text { Meiji 15th-Syowa } \\
\text { 24th }\end{array}$} & \multirow{7}{*}{$1882-1949$} & & Graduated from Chiba Medical College \\
\hline & & & Serving in the Russo-Japanese War for two years \\
\hline & & & 1904 (Meiji 37th) Practicing medicine at home after (Yamada village, Mizunami city) \\
\hline & & Dr. Hanichiro Kato & $\begin{array}{l}1908 \text { (Meiji 41th) Opened Mizunami Hospital, the largest hospital in the Tono region from } \\
\text { the Taisho era to the Showa era (Terakawadocho, Mizunami city) }\end{array}$ \\
\hline & & Died at 67. & $\begin{array}{l}1928 \text { (Showa 3rd) Introduction of deep X-ray irradiation device for the treatment of cancer } \\
\text { and erysipelas }\end{array}$ \\
\hline & & & 1935 (Showa 10th) Commissioned to manage the union hospital, Yoto Hospital \\
\hline & & & $\begin{array}{l}\text { His grandson, Harufumi, was a professor and deputy director of Tokyo Medical } \\
\text { University. }\end{array}$ \\
\hline \multirow{2}{*}{$\begin{array}{l}\text { Meiji 30th-Showa } \\
42 \text { nd }\end{array}$} & \multirow{2}{*}{$1897-1967$} & \multicolumn{2}{|c|}{ Dentist Yutaro Mizuno 1918 (Taisyo 7th) Graduated from Nagoya Dental School and opened in Kamado village } \\
\hline & & Died at 70. & (Mizunami city) \\
\hline \multirow{2}{*}{$\begin{array}{l}\text { Meiji 31st-Heisei } \\
1 \text { st }\end{array}$} & \multirow{2}{*}{ 1898-1989 } & $\begin{array}{l}\text { Midwife Katsu } \\
\text { Watanabe }\end{array}$ & Worked at the Watarai Gynecology Hospital in Kamado village (Mizunami city) \\
\hline & & & 1924 (Taisyo 13th) Opening midwifery business independently \\
\hline
\end{tabular}

Quoted from References [13] [15] [19] [20]. 


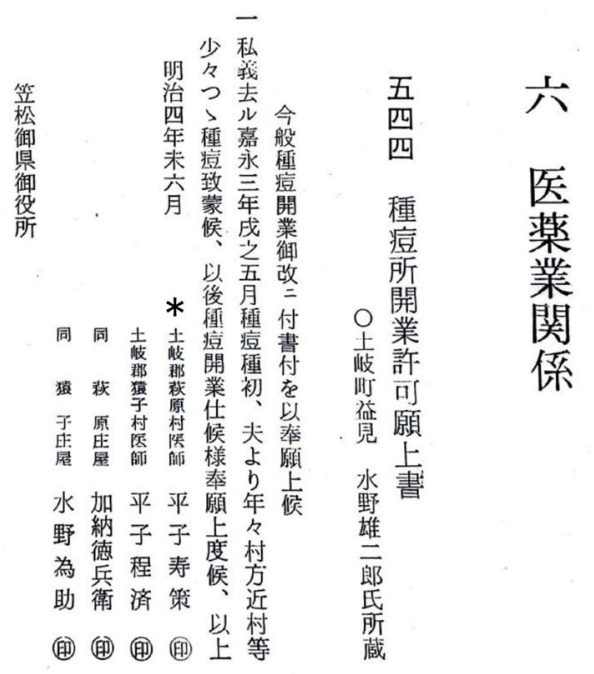

Figure 3. June 1871 (Meiji 4th), the application for permission to open the vaccination institution against smallpox [16]. *The name of Dr. Jyusaku Hirako, in Hagiwara village, Toki district, is listed as an applicant [13].

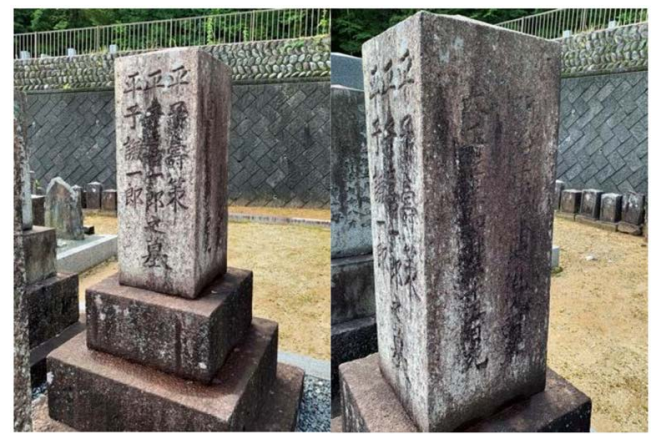

Figure 4. Jyusaku's grave at Koido Reien in Inatsu-cho, Mizunami city. Taken by Shinji Sunada, a member of the Mizunami City Board of Education in July 2020. July 1891, which was dug on the side of the tombstone, is considered to be the year of his death.

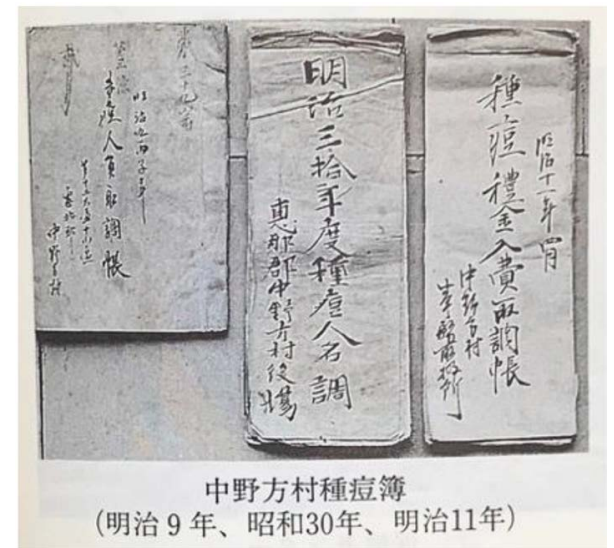

Figure 5. The record book of vaccinations against smallpox in Nakanoho village, Ena city. On the right is an interrogation book for expense for vaccinations, and in the middle is a roster for the vaccination in 1890, which belongs to Nakanoho village [14]. 


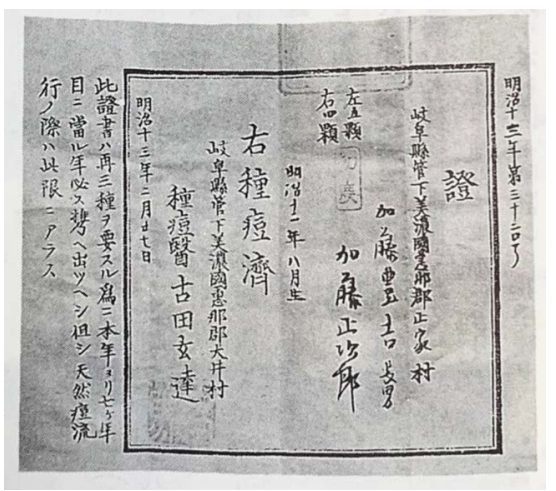

Figure 6. The vaccination certificate in Ena city in 1897. The vaccination doctor is Gentatsu Furuta, however his information is unconfirmed [14].

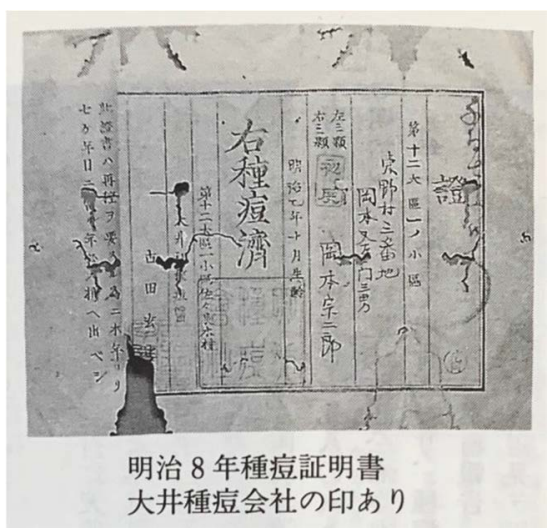

Figure 7. The vaccination certificate with the seal of the pharmaceutical company named Oi Vaccination Company [14].
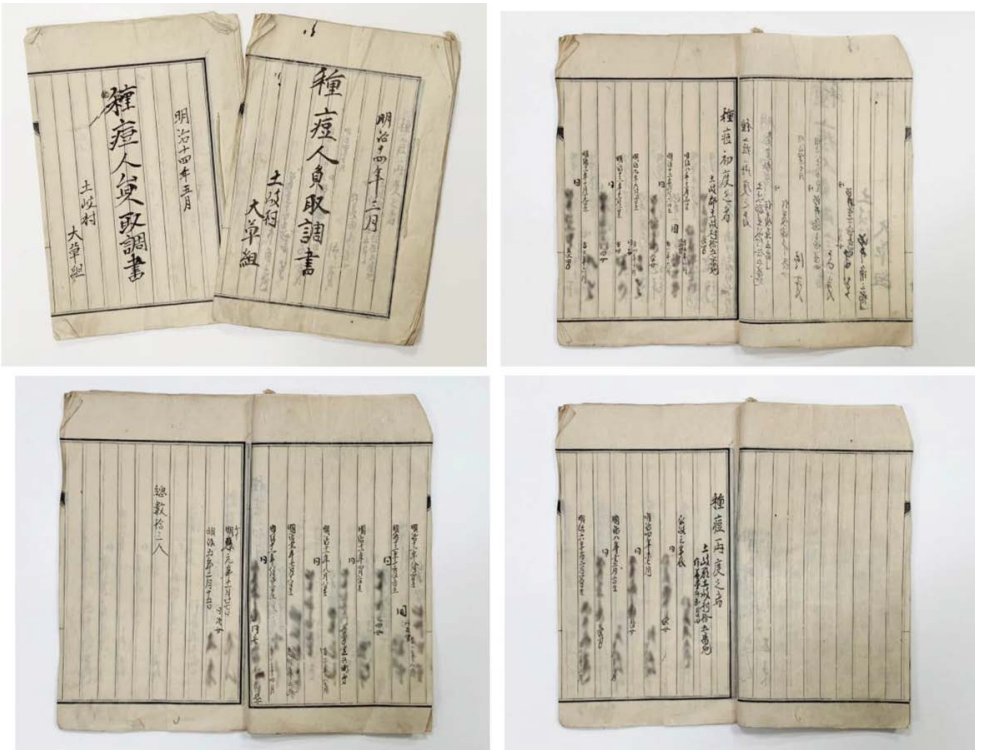

Figure 8. The personnel interrogation report of vaccination against smallpox in 1884. By Okusa Ward in Toki-cho, Mizunami City. Photo by Sinji Sunada, a member of the Mizunami City Board of Education in July 2020. In the document, information on initial vaccination/re-vaccination, surname, date of birth, address, head of household, and relationship is provided. These are unpublished material. 
Midwife Tei Oishi (birth and death years: 1879-1959; Meiji 12th-Showa 34th) entered the midwifery and nurse training center in Gifu prefecture in 1903 and graduated the following year. During the Russo-Japanese War, she worked as a nurse at the Kanazawa Preparatory Hospital and opened a midwifery in Mizunami city in 1905 after the Russo-Japanese War. It is said that she took up more than 400 babies a year as a midwife in about 50 years. In 1942, she was awarded a letter of appreciation by the Gifu branch manager of the Patriotic Women's Association. After the war, he focused on teaching mothers' classes and was active in the housekeepers' association in his later years [13] [19].

Dr. Hanichiro Kato (birth and death years: 1882-1949, Meiji 15th-Syowa 24th) worked as a military doctor during the Russo-Japanese War for two years after graduating from Chiba Medical College. He practiced medicine in Yamada village (Mizunami city) in 1906 (Meiji 39th) (Figure 9) [20]. Mizunami Hospital was opened in 1908 (Meiji 41th) (Figure 10) [20]. From the Taisho era to the Showa era, it was the largest hospital in Tono region. In 1935 (Showa 10th), he was commissioned to manage the union Yoto Hospital (Figure 11) [20]. His grandson, Harufumi, was a professor and deputy director of Tokyo Medical University. Hanichiro introduced a deep X-ray irradiation device in 1928 (Showa $3 \mathrm{rd}$ ) and contributed to the treatment of cancer and erysipelas. Mizunami Hospital still exists today [19] [20].

Dentist Yutaro Mizuno (birth and death years: 1897-1967; Meiji 30th-Showa 42nd) graduated from Nagoya Dental School and opened in Kamado village (Mizunami city) in 1918. Detailed information is unconfirmed [19].

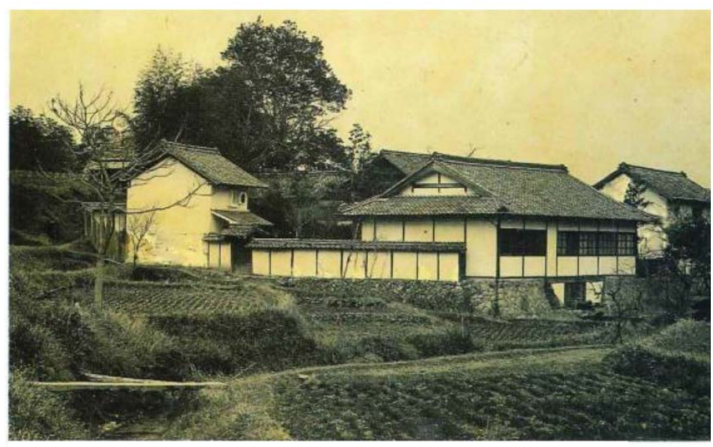

Figure 9. 1904 (Meiji 37th) Practicing medicine at home at Yamada village, Mizunami city [20].

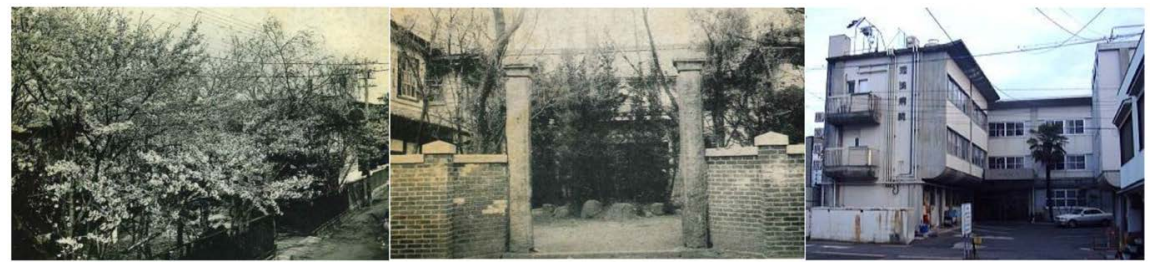

Figure 10. Mizunami Hospital. The photo on the left is from the time when it was opened in 1908 (Meiji 41st), and the photo in the middle is from the Taisho era. The right is the current state [20]. 


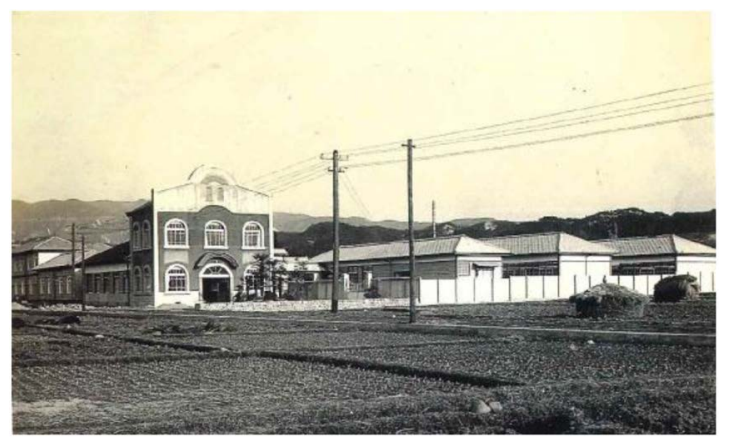

Figure 11. Yoto Hospital in 1935 (Showa 10th) [20].

Midwife Katsu Watanabe (birth and death years: 1898-1989; Meiji 31st-Heisei 1st) worked at the Watarai Gynecology Hospital in Kamado village (Mizunami city) and opened a midwifery independently in 1924 (Taisyo 13th) [19].

\section{Discussion}

In this study, we examined the literature on the epidemic that occurred in the Meiji era and the contributions of healthcare providers who were active in the history of Mizunami city.

1) Trends in research on the epidemic that occurred in Mizunami city and the healthcare providers who fought against it.

There are no materials in Mizunami city that meet the purpose of research using the database. Due to data analysis, it was difficult to obtain materials other than those stored in Mizunami city. There was almost no data on the information before the Meiji era. In the future, interview survey with the cooperation of residents is required for the pre-Meiji era.

2) The outbreak of epidemics in the Meiji era near Mizunami city.

The outbreak of the epidemic near Mizunami city was seen as a fight against smallpox. In addition, cholera, dysentery, Spanish flu, and typhoid fever also occurred. The total population of Japan in the late 1800s in the early Meiji era was about 35 million [3]. Hence, it is possible to predict how high the infection rate was. The epidemics of cholera, dysentery, typhoid fever, and pulmonary tuberculosis infectious diseases that were prevalent in Japan at that time according to other study [3] could be verified in Mizunami city from the materials we obtained. According to other studies, the background of the epidemic's expansion is that the Industrial Revolution forced people to work hard and have an unsanitary living environment, resulting in frequent tuberculosis among weavers and adolescents in the military. Furthermore, the current situation is that it was transmitted from female workers and soldiers who returned home and spread all over the country [3].

For this reason, the expansion of the epidemic involves the social environment such as war, poverty, and labor conditions, and it is also necessary to take measures to improve the environment.

In Japan, in 1846, smallpox became a major epidemic in the Saga domain in 
Kyushu, and Naomasa Nabeshima, the lord of the domain, took cowpox vaccinations from the Netherlands. It is said that it was inoculated in the clan in 1849 and eventually spread nationwide. On the other hand, Koan Ogata also established a smallpox vaccine in Osaka to spread the smallpox vaccine established in the West in 1849 [22].

In this study, it was confirmed that vaccinations were also carried out in the Tono region at the same time. In addition, a cholera epidemic occurred in $\mathrm{Na}$ gano prefecture, and a quarantine branch was established within the Nakatsugawa police station. It was confirmed that the Hygiene Society was transferred from the Interior Department to the Police Department. Under strong centralization, the health care system was expanded.

3) Healthcare providers who were active in the Meiji era (Table 3).

Healthcare providers who were active in the Meiji era include six doctors and two midwives. It was confirmed that Jyusaku, Gendo, who challenged the fight against smallpox, and Hoju and Tsunejiro, who were military doctors and village doctors and saved the lives of the townspeople, were active. It was confirmed that the founder Hanichiro of Mizunami Hospital, which is the largest in the region and has a history of 113 years, and the two midwives of Tei and Katsu were active.

It is known that Dr. Koan Ogata immediately published a book on infection control to educate doctors at the time of the cholera epidemic and that he invested his products to open medical care and varieties [22]. Similarly, in Mizunami, the activities of doctors and midwives who fought against epidemics and their infectious diseases were seen as epidemics.

4) Limitations of research and future issues

The limitation of this research is that the number of documents is limited and the activity before the Edo era could not be confirmed. In the future, it will be necessary to provide more in-depth evidence through surveys such as interviews with the cooperation of relatives of active healthcare providers and local residents who lived there and search for old documents owned by each municipality.

From this research, the success of medical professionals who fought the epidemic in Mizunami as a historical significance reaffirmed the importance of vaccinations and preventive medicine, and made us aware of the importance of working on the development and dissemination of vaccines. It is necessary to institutionalize an appropriate medical system to prevent the spread of epidemics.

\section{Summary}

The outbreak of the epidemic near Mizunami city was seen as a fight against smallpox. In addition, cholera, dysentery, Spanish flu, and typhoid fever also occurred. Vaccinations were carried out in the Tono region. As a measure against infectious diseases, the Hygiene Society office was transferred from the Interior Department to the Police Department. 
In Mizunami city, during an epidemic, there were activities of six doctors and two midwives who fought against epidemics.

\section{Statement of Authorship}

Category 1

1) Conception and Design: Yuko Harding, Sinji Sunada, Masako Yano.

2) Acquisition of Data: Shinji Sunada, Yuko Harding.

Category 2

1) Drafting the Article: Yuko Harding.

2) Revising for Intellectual Content: Yuko Harding, Shinji Sunada, Masako Yano.

Category 3

Final Approval of the Completed Article: Yuko Harding, Shinji Sunada, Masako Yano.

\section{Funding}

This research did not receive any specific grant from funding agencies in the public, commercial, or not-for-profit sectors.

\section{Conflicts of Interest}

The authors declare no conflicts of interest regarding the publication of this paper.

\section{References}

[1] Yokotsuka, Y. (2015) Quarantine Officer Who Fortified the National Border like “Sakimori”. Experimental Medicine, Yudosha, 33, 2868-2873.

https://mol.medicalonline.jp/archive/search?jo=ai4jigkb\&ye $=2015 \& v 0=33 \& i s s u e=1$

https://www.worldstm.com/Toc/ADFD9B88/33/2015/17

[2] Eto, F. (2015) Temptation to the History of 20th Meiji Period Infectious Diseases and Hygiene Administration, 1. Focusing on Cholera, Transition of Infectious Diseases and Modern Western Medicine. Journal of Clinical Rehabilitation, 24, 822-827. https://mol.medicalonline.jp/archive/search?jo $=$ aa7clrie \&ye $=2015 \& v o=24 \& i s s u e=8$

[3] Kobie, A. and Ishiii, N. (2007) "Nursing at Home with Infectious Diseases" Girls' Schools in the Textbook of a Girls' School in the Meiji Era. Journal of North Japan Academy of Nursing Science, 10, 37-44.

https://mol.medicalonline.jp/archive/search?jo $=$ df6nnurs \&ye $=2007 \& v o=10 \& i s s u e=$ 1

https://search.jamas.or.jp/link/bc/20080317400004?from=kango

[4] Part I Overview of Japanese Health Care. 11-12.

https://www.jica.go.jp/jica-ri/IFIC_and_JBICI-Studies/jica-ri/publication/archives/j ica/field/pdf/200403_02_02.pdf

[5] Ministry of Health and Welfare Medical Bureau (1976) The Medical System 100 Years Ago Material Edition. Gyosei. 54-56, 271, 589, 788-792, Ministry of Health, Tokyo. http://id.ndl.go.jp/bib/000001340737

[6] 2020 Lexico.com. https://www.lexico.com/en/definition/epidemic

[7] Segen's Medical Dictionary. () 2012 Farlex, Inc. 
https://medicaldictionary.thefreedictionary.com/healthcare+provider

[8] JAMAS (2019). https://www.jamas.or.jp/english

[9] Medline. https://www.nlm.nih.gov/bsd/medline.html

[10] PubMed. https://www.ncbi.nlm.nih.gov/pmc

[11] Cochrane Library. https://www.cochranelibrary.com

[12] Google Scholar. https://scholar.google.com

[13] Mizunami City (1972) Mizunami City History, History/Historical Materials, Mizunami City. https://ci.nii.ac.jp/ncid/BN14436961?l=en https://www.library.pref.gifu.lg.jp/gifuken-mokuji/mizunami/mokuji_top.htm

[14] Ena City (1993) Ena City History, Overview of the History. Vol. 3 (1), Ena City. https://ci.nii.ac.jp/ncid/BN0349155X?l=en https://www.library.pref.gifu.lg.jp/gifuken-mokuji/ena/mokuji_top.htm

[15] Toki City (1974) Toki City History. 3 (1/2), Toki City. https://ci.nii.ac.jp/ncid/BN06188241?l=en https://www.library.pref.gifu.lg.jp/gifuken-mokuji/toki/mokuji_top.htm

[16] Tajimi City (1987) Tajimi City History, Overview of the History, (2), Tsajimi City. https://ci.nii.ac.jp/ncid/BN01539087?l=en https://www.library.pref.gifu.lg.jp/gifuken-mokuji/tajimi/mokuji_top.htm

[17] Gifu Prefecture (1967) Gifu Prefecture History, Overview of the Modern History, (1), Gifu Prefecture. https://ci.nii.ac.jp/ncid/BA46192989?l=en https://www.library.pref.gifu.lg.jp/gifuken-mokuji/gifuken/mokuji_top.htm

[18] Gifu Prefecture (1972) Gifu Prefecture History, Overview of the Modern History, (2). Gifu Prefecture. https://ci.nii.ac.jp/ncid/BA46192989?l=en https://www.library.pref.gifu.lg.jp/gifuken-mokuji/gifuken/mokuji_top.htm

[19] Mizunami City Retirement Principals Association (1995) Mizunami’s Hometown and Personal History, Mizunami City.

https://iss.ndl.go.jp/books/R100000002-I000002553938-00?ar=4e1f\&locale=en

[20] Medical Corporation Jinaikai Mizunami Hospital (1988) The 80 Years History of Mizunami Hospital, Mizunami City.

https://library.city.mizunami.gifu.jp/WebOpac/spopac/searchdetail.do;jsessionid=6 7E92FB55B6F1BF0D16A18D3BA3EAB59?biblioid=752354\&rownum $=1$ \&termid $=9$ 002\&target=adult\&srchdtl_from $=$ searchlist

[21] Mizunami City Public Library (1996) Nostalgic Photobook. Mizunami City. https://ci.nii.ac.jp/ncid/BA32639980?l=en

[22] Kato, S. (1999) To the Memory of the 150th Anniversary of the Introduction of Jenner's Vaccine into Japan: Documents about Pioneers Who Contributed to Preventive Medicine in Japan. Clinical Virology, 27, 367-377.

https://ci.nii.ac.jp/naid/10009653486/en 